rightly think that Melbourne, from its size and importance, ought to number among its attractions a good zoological collection. If they succeed in obtaining a sufficiently large number of subscribers, they intend, in the first instance, to form as complete a collection as possible of the fauna of Australia, and thereafter, when in a position to do so, to add those of other countries. The Government, we are glad to see, very liberally placed the sum of $\mathrm{r}, 00 \mathrm{o} l$. on the estimate for the past financial year.

A considerable amount of success attended the operations of the society during the year previous to March last. A number of pheasants of the silver (Phaseanus nycthemerus) and common (Phaseanus colchicus) varieties, had been reared, and were to be liberated in suitable places. Upwards of 150 guinea-fowl had been placed in various secluded spots, in forests far removed from settlement, where it is confidently hoped they will increase, and in a few years yield both food and sport.

About 3,500 live trout, hatched at the society's establishment at the Royal Park, Melbourne, had, during the previous season, been placed in different streams. The deer which have been liberaced in many parts of the colony are spreading and increasing rapidly, and the society possess a fine collection of $\mathrm{six}$ varieties in their grounds at the Royal Park. The valuable stock of Angora goats and the ostriches belonging to the society are thriving and increasing.

Although the society is anxious to encourage and promote sericulture, they find it difficult to advance this industry in a really practical manner so as to be of benefit to the colony. Baron von Mueller has, however, as well as the society, supplied many parts of the colony with white mulberry plants, and when they come into bearing, silk growing will, they hope, become an important industry of the colony.

On account of the services rendered to pisciculture by Sir Robert Officer and Mr. Morton Allpart, of Tasmania, the society have awarded to both these gentlemen their silver medal; their bronze medal has been awarded to Captain Babot, of the Hydrastes, for his enterprise in bringing out sea-turtle.

In conclusion, the council are glad to state that the condition of the society is sound and prosperous, and they only require more liberal co-operation from the public to enable them to produce great results in the cause of acclimatisation. We sincerely hope the Australıan public will see it to be to their own interest to respond liberally to the desire of the society for assistance in carrying out their benevolent work.

The bulk of the volum: is occupied by two papers. The first is a valuable monograph on the "Ichthyology of Australia," by Count F. de Castelnau, in which he gives an account of the different sorts obtainable in the Melbourne fish market: their number is 142 . In the introduction the author speaks with great adrniration of Dr. Günther's Catalogue of the Fishes in the British Museum, from which he has continually to quote; further on, he criticises that author's views on the distribution of fishes. He also thinks that the learned doctor is too severely condemnatory of the imperfections of his scientific comrades. The second paper is a list by Baron F. v. Mueller of "Select plants readily eligible for Victorian industrial culture."

\section{NEW FRENCH INSTITUTION FOR THE EXPERIMENTAL SCIENCES}

$A$ MID all her political turmoil and strife it seems to us $A$ a hopeful sign of the real progress of France that she has citizens with energy, enterprise, and enlizhtenment enough to undertake and carry out a scheme of the magnitude and importance of the one about to be realised at Lyons. It is to be exclusively devoted to scientific research, and the Revue Scientifique thinks it deserves to be classed with the richest establishments of a similar kind in England, Germany, and Paris.

For more than a year, it seems, the municipal administrators of Lyons have had it under consideration to form laboratories of physiology and experimental medicine, provided with all the most modern and most approved means of investigation. To settle the plan of such an institution, the muncipality nominated a Commission of scientific men, consisting of MM. Cllier, Perroud, and Tripier. This Commission has given in its report, and the following is the scheme it suggests with regard to the biological sciences alone:-

I. A great central laboratory, equipped for the operations and observations which are required in the experimental study of the physiological and pathological phenomena of the animal economy. In it will be collected and methodically arranged all the instrumental apparatus commonly required for such observations and experiments, especially the registering apparatus.

2. A central hall or store-house of apparatus. This will be the depôt for apparatus and instruments not in daily use, and which are used only in certain circumstances.

3. A laboratory of biological chemistry.

4. A laboratory of biological physics.

5. A laboratory of histology.

6. A room for geological researches relative to the study of parasites and parasitical diseases, including those of the silkworm.

\section{A room for autopsies.}

8. A room for minute dissections and for the mounting of specimens intended to be preserved.

9. A workshop for construction and repairs, in which will also be set agoing the moving forces intended to work the apparatus.

IO. A cabinet of specimens.

I I and I2. A room of design and a small photographic studio.

13. A library.

I4. A hall for mectings and lectures.

15. Places for keeping animals.

16. A conservatory and enclosure for researches in vegetable physiology.

17. General offices, houses for the director and assistants, for fuel, water, \&c.

The pirsonncl comprehends a director and his assistant, a librarıan, who will also see to the publication of the works of the establishment, three assistants, one for operations and autopsies, the second for work in biological physics and chemistry, and the third for microscopic studies and work in experimental zoology ; finally workmen, laboratory at:endants, concierge, groom, \&c.

These laboratories are intended for the study of all the branches of the biological sciences, from general and comparative physiology to experimental medicme, questions of hygiene and public health, diseases of animals (especially silkworms), and vegetable physiology.

But, although specially intended as an institution for the biological sciences, the Commission has indicated that the programme would be rendered complete by adding a physico-chemical institute for the study of brute nature, so as to unite in the same establishment the whole body of modern experimental sciences.

On March 7 the Maire of Lyons presented to the Municipal Council a report asking that the scheme be immediately proceeded with. The city of Lyons has presented the ground of the ancient corn-market on the Qui St. Vinient. According to the $\mathrm{pl}$ ins and estimates of the city architect, the buildings will cost 900,00of., of which this year 330,ooof. have been raised. Finaily, for the biological sciences alone, a first annual budget of 30,00of. has been set aside.

These figures speak for themselves, and need no comment. 